\title{
The Significance of Indigenous Field Education: an Analysis of the Social Workers Advancing Through Grounded Education Program
}

\author{
Kellie Thompson ${ }^{1}$ [D $\cdot$ Lindsey Manshack $^{1}$. Jenifer Van Schuyver ${ }^{1}$
}

Accepted: 13 July 2021 / Published online: 7 September 2021

(c) The Author(s), under exclusive licence to Springer Nature Switzerland AG 2021

\begin{abstract}
The United Nations Declaration on the Rights of Indigenous Peoples (UNDRIP) is predicated on the inherent sovereign rights that all Indigenous peoples have to their lands, cultural practices, and traditional resources prior to colonization and assimilation. However, Indigenous populations continue to be disproportionately affected by inequitable access to education, workforce development, and physical and mental health care. Opportunities for education and workforce development in the field of social work are essential to strengthening Indigenous communities. Indigenous students must often move outside of their communities to pursue master's-level social work degrees, decreasing their opportunity to practice skills within these communities during required master's-level practica. Universities must offer equitable opportunities to Indigenous students wishing to complete practica within Indigenous communities by providing financial support and curricular preparation. In 2014, the Social Workers Advancing through Grounded Education (SAGE) program was created by the Kathryn M. Buder Center for American Indian Studies to provide these opportunities to MSW students, particularly Indigenous students. SAGE consists of recruitment, classroom training, field training, and partnership development. The program has provided financial and educational support to 53 students and created 43 formal partnerships with Indigenous-serving institutions, with nearly $90 \%$ of SAGE recipients identifying as Indigenous. This article presents findings that suggest access to practica with Indigenous populations leads to Indigenous social work students feeling more confident about serving Indigenous communities as social work professionals upon graduation. These results add to literature regarding best practices for creating equitable field education programs suited to enhancing social work in Indigenous communities.
\end{abstract}

Keywords Social work $\cdot$ Indigenous $\cdot$ American Indian · Alaska Native $\cdot$ Human rights $\cdot$ Field education

\section{Introduction}

The United Nations Declaration on the Rights of Indigenous Peoples (UNDRIP) is predicated on the inherent sovereign rights that all Indigenous ${ }^{1}$ peoples have to their lands, cultural practices, and traditional resources prior to colonization and assimilation (The United Nations General Assembly, 2007). UNDRIP is a resolution passed by the General Assembly at the United Nations in 2007 and guarantees that Indigenous rights are documented separately from and in addition to the inherent human rights that all individuals

Kellie Thompson

kellie.thompson@wustl.edu

1 Kathryn M. Buder Center for American Indian Studies, Washington University in St. Louis, St. Louis, MO, USA of this world possess. The Universal Declaration of Human Rights (UDHR) stated that all peoples have inalienable rights such as the rights to freedom, equality, and dignity (UN General Assembly, 1948). UNDRIP stated that Indigenous peoples have the rights to restore cultural practices, restore traditional ways of self-governance, promote their own ways of self-determination, and others (UN General Assembly, 2007). UDHR and UNDRIP validate each other through affirmations of freedoms in expressions, assembly, choice, and education (UN General Assembly, 2007; UN General Assembly, 1948). While these rights have many similarities, the rights of a nation, culture, and community

\footnotetext{
${ }^{1}$ For the purposes of this paper, the terms Indigenous, American Indian/Alaska Native (AI/AN), Native American, and Native will all be used. Indigenous refers to the first original peoples of a land; the other terms are used when referring to the Indigenous peoples of the USA.
} 
are inherent for Indigenous peoples through freedoms of their lands and resources.

UNDRIP is not legally binding and no enforcement agency exists to hold countries and communities accountable for violations. UNDRIP does not give political power to any Indigenous community and it does not address the nation-state perspective, which may lead to disparities and ultimately a need for social workers to address these disparities. However, UNDRIP does offer a guide for governments to utilize while working with Indigenous peoples and more work must be done to fully realize UNDRIP's potential (Burger, 2019; Champagne, 2013). UNDRIP can be used as a tool and best practice for social workers and social work educators as they prepare students to work with and for Indigenous communities. These communities are some of the most at-risk in the world, as well as the most culturally grounded and resilient. Social workers who are knowledgeable about policies and practices and are given the opportunity to practice this work in the community as part of their social work training become better equipped to work with this population post-graduation, addressing disparities and incorporating the strengths of the community in the care delivered.

\section{Human Rights and Indigenous Peoples}

Dunbar-Ortiz (2014) describes colonization as a "culture of conquest - violence, expropriation, destruction and dehumanization" against the Indigenous peoples that Europeans encountered (p. 32). Ultimately, colonization led to the genocide, removal, assimilation, termination, and complete destruction of Indigenous peoples, communities, and lifeways, which created conditions for systemic injustice, racism, intergenerational trauma, and health disparities to develop and continue today. The development of UNDRIP was a response to the ongoing historic and systematic disregard for the human rights of Indigenous peoples. Indigenous populations continue to be disproportionately affected by poverty, poor environmental conditions, and a lack of access to quality physical and mental health care. Over time, these social determinants of health lead to early disease and death (Gracey \& King, 2009). A specific example of this disparity, which is defined as a human rights violation, is the number of missing and murdered Indigenous women. The Centers for Disease Control and Prevention reported that murder is the third leading cause of death among American Indian/ Alaska Native (AI/AN) women and that rates of violence on reservations can be up to 10 times higher than the national average (Urban Indian Health Institute, 2018). In Canada, an Indigenous woman is three times more likely to experience violence in her lifetime and six times more likely to be murdered, according to Amnesty International Canada (ca. 2016), which called this reality a "national human rights crisis" (p.
1). Unfortunately, this human rights crisis example is not new; rather, it is the direct result of historical and systematic practices and policies. This process was described in Reclaiming Power and Place: Final Report of the National Inquiry into Missing and Murdered Indigenous Women and Girls (National Inquiry into Missing and Murdered Indigenous Women and Girls, 2019) arising because of several practices and polices:

Another root cause of the disappearances and deaths of Indigenous women, girls, and 2SLGBTQQIA people is the social and economic conditions in which they live. It is compounded by the lack of political power that systems and institutions have afforded them to speak out. These conditions are a direct result of colonial governments, institutions, systems, and policies that actively work to ensure their social, economic, and related political marginalization. They are rooted in historic dispossession from the land as well as current policies (p. 114).

As the National Inquiry authors noted, the crisis of missing and murdered Indigenous women is the result of complex, historical, and current systems, practices, and policies. Additional human rights violations exist, and Indigenous people face abuse every day (United Nations Department of Economic and Social Affairs. [ca. 2015]). United Nations Department of Social and Economic Affairs [ca. 2015] reported violations, including other types of violence against Indigenous women such as rape, systemic racism, and the criminalization of protest, while Amnesty International (ca. 2019) reported landlessness, malnutrition, and displacement among Indigenous people as human rights issues. Fifteen percent of Indigenous people live in extreme poverty globally, while only accounting for $5 \%$ of the total global population, a disparity that is caused by and compounded by all of the concerns above (Amnesty International, [ca. 2019]).

Social workers are trained to work with communities to develop solutions to address these and other issues of Indigenous human rights crises, and human rights violations and disparities. Their training to work with at-risk populations, their engagement at the local level, and their understanding of how policy affects people are critical. According to the National Association of Social Workers (n.d), the social work profession has a mission to "enhance human well-being and help meet the basic human needs of all people, with particular attention to the needs and empowerment of people who are vulnerable, oppressed, and living in poverty" (p. 1). Social workers hold the responsibility to ensure that all humans have access to the resources and support that they need to live fully realized lives. They have the opportunity to work with their Indigenous clients, who often come from the same tribal community and have similar values and cultural traditions, by advocating through a social justice lens. 
Indigenous social workers are a part of their community and can help uphold inherent sovereignty through the rebuilding and support of programs that are created for Indigenous communities by Indigenous communities. Social workers can perhaps best support Indigenous people by explicitly putting UNDRIP into direct practice and asking communities and clients how they can best advocate for resources and services (Calma \& Priday, 2011). Because of their responsibility to equitable rights and social justice, social workers are in a unique position to work with Indigenous communities to create sustainable, culturally respectful programs (Calma \& Priday, 2011). Indigenous communities need social workers who are knowledgeable about the historical policies that have and continue to affect Indigenous peoples and who are humbled by the unique cultural practices within each community.

\section{Social Work in Indian Country}

This paper focuses on a specific Indigenous population-AI/ ANs in the USA, primarily in the lower 48 states. The term Indian Country has been used to describe tribal governmental jurisdictions, including reservations, Alaska Native villages, trust lands, or areas with a high AI/AN population. Within the USA, there are 5.2 million AI/AN people, approximately $1.7 \%$ of the total US population (U.S. Census Bureau, 2012). With 574 tribes in the USA, disparities exist between tribes. The data provided below represent a geographically and culturally diverse group of AI/AN people. AI/AN people face many of the same human rights violations that other Indigenous populations face, which may include overt or implicit discrimination in health care delivery, quality, and services (World Health Organization, 2017, December 29), "lack of access to basic mental health care and treatment," (World Health Organization, 2005, p. 1) and other forms of discrimination. As sovereign nations, tribes are protected because of UNDRIP. However, in practice, these written protections do not promise equitable treatment and often these violations lead to health and mental health disparities. Mental health disparities include higher than average rates of substance use disorders, posttraumatic stress disorder, suicide, and attachment disorder (American Psychiatric Association, 2017). Due to lack of access and funding of mental health services, historical trauma, and governmental distrust, AI/AN people utilize mental health services less (National Indian Health Board, 2020). The suicide rate among AI/ ANs is higher than that of any other racial or ethnic group. Among AI/ANs 10-24 years old, suicide is 2.5 times higher than the national average, with suicide being the second leading cause of death within this group (National Council on Aging, 2019). Some Alaska Native communities face great barriers to adequate health and mental health care, one of which is their remoteness. There are regional disparities among Alaska Native people. Poverty rates among Alaska Native people range from 15.2 to $34.5 \%$, and suicide rates range from 28.3 per 100,000 people to 65.5 per 100,000 people, depending on the region (Alaska Native Tribal Health Consortium, 2017). The Indian Health Service (IHS, 2019) reported that AI/AN people live on average 5.5 years less than others ( 73 compared to 78.5 years), die from chronic liver disease, diabetes, unintentional injuries, assault, homicide, and suicide at higher than average rates, and experience a higher disease burden than other populations. Additionally, the IHS (2019) reported that disparities exist "perhaps because of inadequate education, disproportionate poverty, discrimination in the delivery of health services, and cultural differences" (para. 2).

$\mathrm{AI} / \mathrm{AN}$ tribes are in a position to utilize tribal sovereignty, self-determination, and UNDRIP to ensure their programs are culturally responsive, respond to community need and are created by the individuals within that community. Culturally respectful social workers in the USA can work to address these human rights issues by working with tribal communities and AI/AN people to support tribal development of programs, policies, and practices to eliminate health and mental health disparities. Social workers have the opportunity to serve clients directly, to create policy for those most in need and to develop new programs for vulnerable populations. It is critical for AI/AN individuals within tribal communities, as well as allies who wish to serve these communities, practice culturally respectful social work, and become leaders within their communities.

\section{Al/AN Social Workers}

AI/AN individuals account for $0.8 \%$ of the total number of active social workers in the USA (Salsberg et al., 2017). Of this number, $49 \%$ hold a non-social work bachelor's degree, approximately $18 \%$ hold a bachelor's in social work, and only $28 \%$ hold master's degrees or greater (Salsberg et al., 2017). These numbers, paired with the ongoing human rights struggles in Indian Country, highlight the need to train $\mathrm{AI} / \mathrm{AN}$ individuals to receive bachelors or master's degrees in social work. This need also highlights the importance of training non-Native social work students as culturally respectful professionals to work within AI/AN communities upon graduation.

However, many barriers exist for students who seek to obtain advanced social work degrees and practice effectively in Indian Country. For AI/AN students, familial, financial, community, and cultural responsibilities may create unique barriers within higher education (Cross et al., 2013, Keith et al., 2017, Thompson et al., 2020). In particular, these students may face different, and sometimes opposing, cultural practices or views within classrooms and field education settings that could interfere with learning. Appropriate content 
may include education around traditional healing practices, cultural and ecological norms, and other Indigenous ways of knowing that have the potential to improve health and educational outcomes for clients (Bessarab, 2015). In an April 2021 draft of the Educational Policy and Accreditation Standards for baccalaureate and master's social work programs revised, the Council on Social Work Education (CSWE) updates competency2, which now states that students must "engage anti-racism, diversity, equity, and inclusion in practice," (CSWE Commission on Accreditation, 2021, p. 4). The document goes on to share that social workers must understand White supremacy and superiority, but AI/AN, or Indigenous-specific curriculum, is still not mandated within these social work standards. This type of learning is critical for both AI/AN and non- AI/AN social work students who wish to work in Indian Country. Bessarab (2015) reports on Australian Indigenous social work education:

Our role and responsibility as social workers is to embed Aboriginal and Torres Strait Islanders worldviews into our work with Aboriginal and Torres Strait Islander peoples in culturally responsive ways that can facilitate their healing process in becoming a whole person (p. 3).

Bessarab's belief that it is the role and responsibility of educators to embed this type of learning into existing systems is important. Within social work, field education is the primary mode of learning for students and serves the purpose of "preparing students in the profession's fundamental ways of thinking, performing, and acting with integrity" (Wayne et al., 2010, p. 327). AI/AN field education, or practice-based learning opportunities with AI/AN peoples and organizations, may not be readily available for students in master's of social work (MSW) programs. Additional research in Canada suggested that reflexivity, relationships, and structural policy changes in schools offering practicum opportunities with Indigenous communities are necessary to transform social work education, creating the space for Indigenous students to succeed in a system that embraces Indigenous perspectives and worldviews (Clark \& Drolet, 2014).

AI/AN student learning fundamentally incorporates core values, identity, holistic wellness, academic excellence, and relationships (Native American Community Academy Inspired Schools Network [NISN] [ca. 2016]). Activities recommended by NISN (ca. 2016) prepare students to be leaders, in relationship with others, to be balanced, to be connected to the land, to (re)learn languages, and to learn/ practice culture, and they are all built on a foundation of core values, which include modeling, service learning, cultural safety, and connection to student behavior. Learning within an AI/AN context is about doing, practicing, and understanding, which has been passed down from generation to generation. Elders play a significant role in the passing of knowledge within communities and are valued for the wisdom they possess, hold, and share with younger generations. $\mathrm{AI} / \mathrm{AN}$ values must be central in this process as they guide what is learned and practiced. Harris and Wasilewski (2004) shared four central values of AI/AN communities relationship, responsibility, reciprocity, and redistribution. Social workers addressing human rights issues in $\mathrm{AI} / \mathrm{AN}$ communities may see that MSW field education and AI/AN learning methods complement each other; both incorporate doing, practicing, and learning skills, as well as values and identity within both domains - the population being served and the pedagogy being taught. Bessarab (2015) goes further to describe the importance of Indigenous knowledge in social work education and advocates for social workers to become culturally responsive in their work with Australian Aboriginal clients. Young et al. (2013) conducted a systematic literature review and created The Getting It Right: Creating Partnerships for Change Framework. This framework posits that social work education must equally value Indigenous ways of knowing, being, and doing; be Indigenouscentered; be created in collaboration with the community; be culturally respectful to Indigenous people; be based on Indigenous pedagogy; and be taught to all social work students. The Social Workers Advancing through Grounded Education program (SAGE), created by the Kathryn M. Buder Center for American Indian Studies, was developed within a social work program to incorporate these important aspects of Indigenous education and learning.

\section{Social Workers Advancing Through the Grounded Education (SAGE) Program}

Young et al.'s (2013) framework underscores the importance of engaging with Indigenous communities as strategies for creating meaningful partnerships for change are created. It is important to work across programs and implement multilevel partnerships between educational institutions and community partnerships to be mutually beneficial (Maurrasse, 2002). In 2014, the Kathryn M. Buder Center for American Indian Studies at the Brown School at Washington University in St. Louis created the SAGE program with the goal of increasing opportunities for social work students to access AI/AN practica by providing financial support and curricular preparation. The program has and continues to focus its recruitment efforts on $\mathrm{AI} / \mathrm{AN}$ students. SAGE is directed by $\mathrm{AI} / \mathrm{AN}$ staff, who are committed to the communities they and their students intend to work within. SAGE is further supported by a network of partners, outside and within the Brown School, such as the Office of Admissions and Recruitment, Office of Field Education, Academic and Student Affairs, Finance Department, Career Services, the Communication Lab, and 
multiple community partnerships. The SAGE program is a holistic approach to AI/AN student support and development, with staff overseeing the recruitment, classroom training, field training, and partnership development portions, all essential for relationship development, student satisfaction, and sustainability.

\section{Recruitment}

A partnership between the SAGE program and the Office of Admissions and Recruitment was created to streamline applicants to the school who may be interested in working with AI/AN populations. This partnership also allows the SAGE program additional opportunities to promote field education in Indian Country through the Office of Admissions while they travel on recruitment trips. The Office promotes SAGE and shares materials with prospective applicants to the Brown School. Through yearly visits to tribal colleges and universities, information regarding the SAGE program is shared with potential applicants who are looking for MSW programs. Recruitment fairs and career days allow information regarding the SAGE program to be shared to wider audiences that may not have considered social work as a career. SAGE and Buder alumni widely share information about the program with potential candidates who are dedicated to serving in Indian Country. Finally, the SAGE program information is disseminated to all current Brown School students. Developing trusting relationships with students early and maintaining this level of commitment is critical to the success of the SAGE program. The Buder Center has graduated over $200 \mathrm{AI} / \mathrm{AN}$ students since 1990, many working as professional social workers in the field today. The SAGE program supported approximately $25 \%$ of these students over five years of the Center's 30-year history. Alumni of the program continue on to be field supervisors for current SAGE participants, assist in recruitment, and provide learning opportunities for students.

\section{Classroom Training}

Students must complete courses within the AI/AN concentration at the Brown School prior to their field education placement. These offerings were created to provide students with curriculum focused on the changing needs within AI/AN communities, based on conversations with AI/AN practitioners and best practices created by these communities. Courses are primarily taught by AI/AN instructors, cover the current climate and historical background of AI/AN communities, and are intended to prepare students to understand topics such as social work, equity, justice, disparities, tribal sovereignty, community development, and practice. A partnership with the AI/AN concentration chair ensures that courses are available for SAGE students to take each semester. Additionally, other educational opportunities to further learning are provided to SAGE students, such as The Current State of the Indian Child Welfare Act training. Four courses were offered each year between 2014 and 2019:

- Leadership Development and Evaluation in Indian Country. This course shared Indigenous leadership styles and concepts to students and allowed students to explore and analyze their own leadership styles and abilities through the planning and implementation of a group-coordinated program.

- American Indian Societies, Cultures and Values. This course grounded students in understanding American Indian societies, cultures, and values, including the diversity among tribal populations and Indigenous theories of social work.

- Community Development with American Indian and other Indigenous Communities. This practice course provided students with knowledge and skills concerning the process of community development in Indigenous communities and included a trip to a tribal community to visit and meet with members living and working in the community.

- Social Work and American Indians. This course provided a professional social work framework for guiding social work practice with AI/AN people. Central themes included relationships, empowerment, cultural, and political uniqueness of AI/AN people and diversity.

- Indigenous Mental Health Practice. This course provided an understanding of Indigenous mental health conceptualizations, delivery systems, programs, and interventions available to those working with Indigenous populations and incorporated activities to engage students as Indigenous practitioners.

- American Indian Social Welfare Policies and Administrative Practices. This course focuses on historical and contemporary policies and administrative practices in the delivery of services to AI/AN communities. AI/AN sovereignty, policy models, processes, and their impacts were the focus.

The variety of courses offered allows students to selfselect courses they find most appropriate for their long-term career goals and that will help them prepare for their field education placement.

\section{Partnership Development}

Developing sustainable partnerships is vital in Indian Country and in geographical regions, often urban, that may have a high number of AI/AN people but have a small number of AI/AN serving sites. It can lead to long-term sustainable impact in $\mathrm{AI} / \mathrm{AN}$ communities and ensure that students have 
field education opportunities. Partnerships are built with field education placement in mind and serve as a pipeline for students, providing a network of connection and relationships. Partnerships are created to be reciprocal, an AI/AN value, which means they are mutually beneficial to both partners. Sites benefit from hosting a practicum student with no anticipated financial cost, and they have access to resources, including professional development trainings, online libraries, and job opportunities posted at the Brown School. Sites work directly with the Brown School's Office of Field Education and the SAGE program staff to ensure that students are prepared for practica. Between fall 2014 and fall 2019, the SAGE program created formal, Brown School-affiliated partnerships with 43 sites. These sites hosted SAGE participants as practicum students across 19 states. Participants completed their field education practicum with a variety of sites, including tribal organizations, non-profit organizations, academic institutions, community-based organizations, community mental health centers, tribal governments, federal government offices or agencies, community health centers, and other sites.

The 43 SAGE sites served multiple populations, including tribal, low income persons, families, adolescents, children, transitional age youth, victims of abuse or trauma, people with disabilities, unemployed persons, LGBTQ persons, college students, homeless individuals, military and/ or military families, individuals with HIV/AIDS, migrant workers, older adults, refugees, undocumented immigrants, uninsured/underinsured, chronically ill and pregnant women, and infants. The SAGE program has developed over 50 informal partnerships, in addition to the 43 formal partnership sites. Based upon the number of partnerships, there is a clear demand for more social workers in Indian Country. SAGE program staff have witnessed that the demand for social workers in Indian Country exceeds the number of social workers available and social work students who can commit to completing their practica's in Indian Country, leaving gaps in services.

\section{Field Training}

The program is built upon the foundation that students will participate in important programs when they have access to opportunities to practice their skills and learn in an environment that fosters growth and learning (Connaughton, Lawrence, \& Ruben, 2003; Dugan, Komives, \& Segar, 2009). Schools of social work consider these opportunities field education and they create unique opportunities for students to put into practice what they learn within the classroom. Universities must offer equitable opportunities to Indigenous students wishing to complete practica in Indigenous communities by providing support and curricular preparation. The SAGE program financially supports students while they complete $360 \mathrm{~h}$ of their total required field education practicum, or three credits, with an $\mathrm{AI} / \mathrm{AN}$ site that serves AI/AN populations. Work tasks align with and benefit a community's knowledge, research, or direct practice. Students are mentored to reach out directly to sites, and SAGE staff assist them in navigating potential opportunities with partners.

The SAGE program is intended to prepare social work students to practice in Indian Country by creating important field education opportunities. The aims of this paper are to report SAGE program quantitative and qualitative results of all components of the program, including demographic data and pre- and post-survey results. Questions analyzed primarily focus on student field training and measure if access to practica with Indigenous populations affects AI/AN student confidence, understanding, preparedness, and knowledge to serve their AI/AN communities. Authors hypothesized that the SAGE program would increase student confidence, understanding, preparedness, knowledge, and the observed value of experiential learning. These results add to the literature in how best to create opportunities for Indigenous social work students seeking to eliminate human rights violations in $\mathrm{AI} / \mathrm{AN}$ communities.

\section{Methods}

\section{Instruments}

A trained research assistant administered pre-surveys prior to practicum initiation and participant responses were added into a Microsoft Excel spreadsheet. After completion of the practicum, participants completed the post-survey with the same questions. The survey questions were developed by SAGE staff to measure student awareness, confidence, and knowledge before and after the practicum. Approval by the Washington University in St. Louis Institutional Review Board was obtained for all study procedures.

\section{Study Sample}

Between 2014 and 2019, 53 students participated in the SAGE program; $87 \%$ self-identified as AI/AN or Indigenous $(n=46)$, while $13 \%$ self-identified as non-AI/AN or non-Indigenous $(n=7)$. Fifteen percent were male $(n$ $=8)$ and $85 \%$ were female $(n=45)$. All participants were graduate level students at the Brown School at Washington University in St. Louis. Of the 53 participants, 87\% were enrolled in the Master of Social Work (MSW) ( $n$ $=46), 7 \%$ Master of Public Health $(\mathrm{MPH})(n=4)$, and $6 \%$ Other Master $(n=3)$ degree programs. All participants completed at least two AI/AN concentration courses and completed three credits of their total field education practicum serving AI/AN populations. Students completed 
this practicum over the course of one summer, between 2015 and 2019. Eight students participated in the SAGE program in 2015, 15 students in 2016, nine in 2017, 16 in 2018, and five in 2019.

All 53 participants completed the pre-survey and 50 completed the post-survey. The three individuals lost to follow-up were removed from the final analysis. Three open-ended questions were added to post-surveys in 2019. Qualitative data is from five SAGE participants from 2019.

\section{Measures}

Quantitative participant data were gathered using preand post-surveys. SAGE participants were asked to indicate their level of agreement or disagreement with Likert scale statements, ranging from strongly agree to strongly disagree.

The following six statements were measured and analyzed.

- I feel confident about working in Indian Country.

- I fully understand AI/AN culture.

- I am prepared to work in Indian Country.

- I am confident of my skills to be successful in Indian Country.

- I know the history of child welfare in Indian Country.

- Experiential learning is valuable and adds to my career goals.

Qualitative participant data was collected on the post-survey through open-ended questions beginning in 2019. These questions were developed to investigate specific professional and personal skills gained during the SAGE program that were not captured in the quantitative analysis.

Responses to the following two questions are included in the final results.

- Please tell us one valuable professional skill, competency, or experience you gained during your SAGE practicum.
- Please tell us one valuable personal skill, competency, or experience you gained during your SAGE practicum.

\section{Results}

Quantitative survey results were analyzed to determine whether post-survey responses showed a change in confidence, understanding, preparedness, knowledge, and experiential learning value as compared to the pre-survey responses. Descriptive statistics compared pre- and postsurvey responses. Analysis of responses $(n=50)$ found that the mean response between the pre- and post-survey questions demonstrated increases in confidence, understanding, preparedness, and knowledge statements. The analysis of the statement regarding experiential learning $(n=42)$ indicated a slight decrease in mean. Results from all statements are found in Table 1.

Qualitative data were collected from open-ended questions from five participants. Responses from all five participants are included below, with two tables listing specific skills mentioned by participants.

\section{Professional Skills Gained (Table 2)}

The SAGE program field training provided participants with real-world opportunities to practice and develop their professional social work skills in communities they intend to serve (see Table 2). Many participants shared that hands on research with AI/AN people and organizations was a critical aspect of their practicum. For example, qualitative and quantitative research, evaluation, and implementation science skills were practiced and learned. Another participant mentioned community-based participatory research, which has been shown as a strength-based framework for research with Indigenous communities. Additionally, one participant shared the need for funders to be challenged in evaluation requirements to ensure evaluations are culturally aligned and relevant to a specific tribal community.

The opportunity to complete practicum in Indian Country allowed participants to use their classroom knowledge within Indigenous communities in a way that benefitted these
Table 1 Descriptive statistics for pre- and post-surveys

\begin{tabular}{|c|c|c|c|c|c|c|}
\hline & \multicolumn{3}{|c|}{ Pre-survey } & \multicolumn{3}{|c|}{ Post-survey } \\
\hline & M & SD & $n$ & M & SD & $n$ \\
\hline I feel confident about working in Indian Country & 4.12 & .746 & 50 & 4.52 & .614 & 50 \\
\hline I fully understand AI/AN culture & 3.46 & 1.182 & 50 & 4.00 & .904 & 50 \\
\hline I am prepared to work in Indian Country & 4.00 & .782 & 50 & 4.44 & .675 & 50 \\
\hline I am confident of my skills to be successful in Indian Country & 4.10 & .789 & 50 & 4.54 & .762 & 50 \\
\hline I know the history of child welfare in Indian Country & 4.10 & .743 & 50 & 4.46 & .646 & 50 \\
\hline Experiential learning is valuable and adds to my career goals & 4.93 & .261 & 42 & 4.83 & .490 & 42 \\
\hline
\end{tabular}


Table 2 Participant responses of professional skills gained

Qualitative research

Knowledge of evaluation in practice

Process of community-based participatory research

Implementation science

Working with clients and families

Community skills with clients and families

Using what they learned at the Brown School and making it relevant to Indigenous peoples

Case management experience

Best practices of their field sites organization such as learning about the organizations case management data system

Best practices of coordination of formal and informal activities, services, and support to optimize the well-being of TANF participants

Successful work with other programs housed within field site agency

Helping clients meet their physical, emotional, mental, and spiritual needs

Administer naloxone for opioid overdose

Assessing clients and setting appropriate boundaries

communities. This is a primary goal of the SAGE program and this outcome was seen in participant responses. One participant noted "I feel [SAGE] really helped me use what I learned at Brown School but use it in a way that is relevant to Indigenous peoples." Another professional skill noted was the importance of relationship building and strengthening individual/community partnerships with tribal communities. Additionally, the real-world experience of working within a tribal organization allowed participants to observe how a behavioral health organization serving tribal communities operates. A participant noted, "Through casework management, I learned the best practices of the organization and coordination of network both formal and informal activities, services, and supports designed to optimize the well-being of TANF participants."

\section{Personal Skills Gained (Table 3)}

Building strong relationships with the community was also a personal skill two participants spoke about gaining during their SAGE practicum. Specifically, the development of personal communication skills helped strengthen the relationship between the participant and community. One participant noted that they "Developed and enhanced communication skills and learned how to assist participant families through listening skills and exercising interpersonal communication skills." Storytelling is commonly used within Indigenous communities to share information. One participant mentioned they learned the "value of storytelling in building relationships-whether with your coworkers or people you are interviewing." Participants developed these skills and one participant also shared that they realized the importance of including their own cultural background into their work. They stated, "I learned it is important to maintain my cultural practices and continue to reclaim my ceremonies, language, and culture in order to be a healthy social work practitioner and human being. I started learning my language and songs because it is important to perpetuate my culture." Through practicing and integrating personal culture in to the work, students continued to develop the skills and values that are the foundation of the SAGE program (Table 3).

Table 3 Participant responses of personal skills gained

Learned to challenge funders (ex. CDC) on evaluation requirements that are culturally misaligned

The value of storytelling in building relationships (with coworkers or clients)

Exposed to different [Indigenous] cultures and cultural struggles

Witnessed the importance of representation in research institutions

Experience working with urban Native populations

Experience interacting one-on-one with TANF participants and families

Developed and enhanced communication skills

Learned how to assist [TANF] families through listening skills and exercising interpersonal communication skills

Opportunity to realize the importance of maintaining one's own cultural practices and continuing to reclaim their own ceremonies, language, and culture in order to be a healthy social work practitioner and human being

Opportunity to learn their traditional, tribal language and songs 


\section{Discussion}

The data collected show that access to practica with Indigenous populations may lead to increased levels of confidence, preparedness, knowledge, and understanding of a variety of topics, which are important when working within AI/AN communities. Increases were seen in the confidence statements, which include "I feel confident about working in Indian Country" and "I am confident of my skills to be successful in Indian Country." These confidence measures are intended to highlight that access to and participation in an AI/AN practica settings could lead to increased confidence in social work skill delivery within AI/AN community social workers. Confidence to be a social worker and confidence in the skills needed to work in specific communities is critical for community healing, individual healing, and development. Increased confidence among social workers is linked to higher emotional regulation and ability to recall information from the classroom at a higher rate compared with those who express lower confidence in a specific area of practice (Bogo et al., 2017). Students' confidence in themselves and their ability to bring their cultural knowledge into the field can lead to community trust and development.

Increases were also seen in the following statements, "I fully understand AI/AN culture," "I am prepared to work in Indian Country," and "I know the history of child welfare in Indian Country." It is important to note that anecdotally many SAGE participants commented on the statement regarding AI/AN cultural understanding. They suggested it be reworded because having full understanding of AI/ AN culture may not be possible, even if someone is a part of an AI/AN community. SAGE program staff noted that although cultural understanding was the lowest among all statements, it increased more than the other statements. The final statement "Experiential learning is valuable and adds to my career goals" showed a small decrease between pre- and post-surveys, although the means of both responses indicate on average participants strongly agree that experiential learning is valuable.

Qualitative findings show the range of skills and knowledge gained by SAGE program participants. Some include research skills, evaluation practice, community-based participatory research, Indigenous motivational interviewing, practice being a professional in a large organization, struggles of urban AI/AN communities, TANF participant interactions, cultural self-reflection, and the importance of one's own culture in being a successful social worker. These sites gave SAGE participants an opportunity to work directly with populations most in need of social services, including minority and underserved peoples. Qualitative findings are limited due to the late inclusion of these questions; however, they give voice and specific understanding to the quantitative questions analyzed above.

Both quantitative and qualitative findings are critical because responses provided underscore the importance of training with the populations that graduate students plan to serve after graduation. Offices of field education and social work educators should feel encouraged to plan field education experiences for students wishing to work with AI/AN people and communities as they have the potential to influence student learning and community capacity. Using the SAGE program model, which includes recruitment of AI/ AN students, partnerships with AI/AN organizations, AI/ AN curriculum, and AI/AN field education opportunities to develop these efforts will provide schools a unique opportunity to impact communities and decrease human rights violations that occur in Indian Country. SAGE program staff have observed positive short-term results; it has led to more partnerships with $\mathrm{AI} / \mathrm{AN}$-serving field education sites, created more interest from all Brown School students to complete their field training with AI/AN serving sites, led to additional inquiries from prospective students interested in working with AI/AN populations, and developed more culturally trained social workers. The SAGE program incorporates Indigenous ways of learning into the classroom, as described above, into field education and into program development. All four aspects of the program were critical not only to ensure participants success, but also to ensure communities' needs were self-identified and capacity was increased. Because of the SAGE program's 53 participants, approximately 19,080 additional hours were served at practicum sites in Indian Country.

The SAGE program is one way for AI/AN students to practice their own self-determination as they select field sites. And as shared, to fully realize UNDRIP's potential of ensuring Indigenous people's rights to land, cultural practices, and traditional resources, more work must be done (Burger, 2019; Champagne, 2013). A critical piece of this work is to ensure social workers are equipped with the understanding and knowledge of AI/AN sovereignty and how this affects social work. The SAGE program provides a foundation for social work students to learn about tribal sovereignty and practice it within the communities they select for their field practicum. The AIAN-focused courses provide the skills and knowledge for social workers to center human rights issues, disparities, and AI/AN community-created solutions, while providing flexibility to focus on a specific issue. By completing field practica within their own or another AI/AN community, SAGE participants were able to observe best practices from other social workers that have worked in the community and in the field that they will soon be entering. The Indigenous way of learning through doing is used here. When a student observes a 
community practicing tribal sovereignty to address human rights, and participates when invited, UNDRIP's potential is realized. It is the responsibility of the student to retain this training and make certain that each community they work within has the capacity for such work. It is essential that schools of social work provide this type of comprehensive, culturally relevant curriculum, and training and field training opportunities to all social work students because, in order to protect rights, UNDRIP must first be known. The SAGE program adds to the limited literature on Indigenous knowledge and Indigenous fieldwork within Western educational systems as one avenue to protect $\mathrm{AI} / \mathrm{AN}$ human rights and self-determination.

The COVID-19 pandemic has created many challenges for tribal nations, AI/AN organizations, communities, and schools, as well as MSW students. Higher incidence rates of COVID-19 within AI/AN communities will have longterm health and mental health effects on the populations and highlight the human rights issues within tribal communities. One struggle is the health and safety of Indigenous women. As described above, this subset of the Indigenous population faces significant disparities and injustices. COVID-19 has highlighted, as well as compounded, this burden. Indigenous women are less likely to be insured, more vulnerable to complications from COVID-19 due to preexisting conditions, and more likely to be exposed to violence in their lifetime (United Nations Entity for Gender Equality and the Empowerment of Women, 2020). Diallo et al. (2020) recommends a comprehensive plan in which governments implement steps to ensure women are protected against human rights violations and discrimination, "including by advancing indigenous women's participation in public life; free, prior and informed consent; bodily autonomy; self-determination and collective and individual rights." AI/AN MSW students continue to seek field placements within organizations with goals such as these. To implement and serve populations, COVID-19 has highlighted the need for telehealth within communities, as well as telehealth opportunities for MSW students seeking practica. Many sites have adopted the use of telehealth and are working with SAGE students to continue providing opportunities, highlighting the resiliency and flexibility of $\mathrm{AI} / \mathrm{AN}$ people and organizations.

\section{Implications/Improvements}

An iterative approach has been used to develop the SAGE program. As a result of funder guidelines, some aspects of the program have been adjusted over time. Funding for the SAGE program is essential now for the social work students at the Brown School as they complete AI/AN field education during a global pandemic and as learning opportunities change as a result. Funding and capacity for this type of work must be at the forefront within graduate-level schools of social work. Strategic efforts to provide cultural and financial support to students committed to working in Indian Country and with AI/AN peoples must occur.

Additional research is needed on the distinct, separate affect that classroom training and field training have on student confidence, preparedness, knowledge and understanding, as well as humility within this cultural context. Additionally, this study used a non-validated Likert scale survey tool. Future research should build validated data collection tools specialized in measuring field education and AI/AN cultural understanding. The purpose of this study was to measure student confidence, preparedness, knowledge, and understanding before and after the 360-h field practicum experience. Future research will be incorporated to measure how AI/AN classroom training is associated with student learning.

\section{Conclusion}

Indigenous people today live in a time in which cultural traditions, human rights, and sovereignty are simultaneously but, paradoxically, being threatened and recognized. UNDRIP offers this critical recognition and understanding of human rights within Indigenous populations. Fourteen years after its development, UNDRIP continues to serve as a starting point by providing common language for eliminating disparities, human rights violations, and other injustices that communities identify.

The SAGE program has created opportunities to better understand and address human rights within Indigenous communities in many ways. First, it builds the immediate capacity to support Indigenous students, communities, and organizations to allow students to travel to these communities to complete their fieldwork. These students bring with them knowledge, passion, and a desire to better the lives of Indigenous people, in many cases their own communities. Indigenous organizations will receive a reciprocal benefit from having these students serve their community. For long-term impact, students will work in these Indigenous communities after they receive their degrees. Second, this program helps prepare social work students to recognize and create appropriate cultural solutions to human rights violations within Indigenous communities. Creating opportunities for social work students to learn about human rights issues and practice critical cultural reflection alongside communities to address human rights violations is imperative for successful social work education and in line with the new anti-racist field standards. Third, it provides the educational institution an opportunity to model human rights work. Identifying and working within an Indigenous framework will show students that the work 
is not only occurring externally but also internally. In this context, the SAGE program breaks down barriers for Indigenous students and communities to serve their own populations. Finally, it creates trusting, long-lasting partnerships between educational institutions and Indigenous groups and organizations. It not only creates necessary, important relationships for this work to happen, but it also creates accountability for non-Indigenous organizations to acknowledge their responsibility in addressing human rights violations. Rather than distancing themselves, nonIndigenous organizations will share the responsibility of finding solutions with Indigenous peoples, creating mutual accountability.

UNDRIP's recognition is critical; however, additional steps are needed to ensure Indigenous peoples' human rights are met, especially in a post-COVID-19 world. Social work educators play a pivotal role in preparing students to serve Indigenous communities. Schools of social work may look to adopt an Indigenous field education framework and incorporate aspects of NISN's (n.d.) values, Bessarab's (2015) reflection, Young et al.'s (2013) framework, or the SAGE program described in this paper to prepare their students to serve Indigenous populations.

\section{References}

Alaska Native Epidemiology Center. (2017). Alaska Native health status report: Second edition. Alaska Native Tribal Health Consortium. https://anthctoday.org/epicenter/publications/ HealthStatusReport/AN_HealthStatusReport_FINAL2017.pdf

American Psychiatric Association. (2017). Mental health disparities: American Indians and Alaska Natives. https://www.psychiatry. org/File\%20Library/Psychiatrists/Cultural-Competency/MentalHealth-Disparities/Mental-Health-Facts-for-American-IndianAlaska-Natives.pdf

Amnesty International. (2019). Indigenous peoples. https://www.amnesty. org/en/what-we-do/indigenous-peoples/

Amnesty International Canada. (2016). No more stolen sisters: Human rights crisis. https://www.amnesty.ca/ourwork/campaigns/nomore-stolen-sisters/human-rights-crisis

Bessarab, D. (2015). Changing how and what we do: The significance of embedding Aboriginal and Torres Strait Islander ways of knowing, being, and doing in social work education and practice. Australian Social Work, 65(1), 1-4. https://doi.org/10.1080/0312407X. 2015.973475

Bogo, M., Regehr, C., Baird, S., Paterson, J., \& LeBlanc, V. (2017). Cognitive and affective elements of practice confidence in social work students and practitioners. British Journal of Social Work, 47(3), 701-718. https://doi.org/10.1093/bjsw/bcw026

Burger, J. (2019). After the Declaration: Next steps for the protection of indigenous peoples' rights. The International Journal of Human Rights, 23(1-2), 22-33. https://doi.org/10.1080/13642987.2018.1562916

Calma, T., \& Priday, E. (2011). Putting Indigenous human rights into social work practice. Australian Social Work, 64(2), 147-155. https://doi.org/10.1080/0312407X.2011.575920

Champagne, D. (2013). UNDRIP (United Nations Declaration on the Rights of Indigenous Peoples): Human, civil, and Indigenous rights. Wicazo Sa Review, 28(1), 9-22. https://doi.org/10.5749/ wicazosareview.28.1.0009

Clark, N., \& Drolet, J. (2014). "Melq'ilwiye" coming together: Reflections on the journey towards Indigenous social work field education. Currents: Scholarship in the Human Services, 13(1). https:// journalhosting.ucalgary.ca/index.php/currents/article/view/15951

Connaughton, S. L., Lawrence, F. L., \& Ruben, B. D. (2003). Leadership development as a systematic and multidisciplinary enterprise. Journal of Education for Business, 79(1), 46-51

Council on Social Work Education Commission on Accreditation. (2021). 2022 Educational Policy and Accreditation Standards (EPAS) - Draft 1, 1-32. https://www.cswe.org/getattachment/ Accreditation/Information/2022-EPAS/EPAS-2022-Draft-1-April2021-(2).pdf.aspx

Cross, S. L., Day, A., Gogliotti, L. J., \& Pung, J. J. (2013). Challenges to recruit and retain American Indian and Alaskan Natives into social work programs: The impact on the child welfare workforce. Child Welfare, 92(4), 31-53. https://europepmc. org/article/med/24851474

Diallo, B., Qayum, S., \& Staab, S. (2020). COVID-19 and the care economy: Immediate action and structural transformation for a gender-responsive recovery. Gender and COVID-19 Policy Brief Series. UN Women. https://www.unwomen.org/en/digitallibrary/publications/2020/06/policy-brief-covid-19-and-thecare-economy

Dugan, J. P., Komives, S. R., \& Segar, T. C. (2009). College student capacity for socially responsible leadership: Understanding norms and influences of race, gender, and sexual orientation. Journal of Student Affairs Research and Practice, 45(4), 927-952

Dunbar-Ortiz, R. (2014). An indigenous peoples' history of the United States (Vol. 3). Beacon Press.

Gracey, M., \& King, M. (2009). Indigenous health part 1: Determinants and disease patterns. The Lancet, 374(9683), P65-75. https://doi.org/10.1016/S0140-6736(09)60914-4

Harris, L. D., \& Wasilewski, J. (2004). Indigeneity, an alternative worldview: Four R's (relationship, responsibility, reciprocity, redistribution) vs. two P's (power and profit). Sharing the journey towards conscious evolution. Systems Research and Behavioral Science, 21(5), 489-503. https://doi.org/10.1002/sres.631

Keith, J. F., Stastny, S., Agnew, W., \& Brunt, A. (2017). Effects of a culturally relevant educational intervention on retention among American Indian tribal college students. Tribal College Journal of American Indian Higher Education, 29(1), n1. https://tribalcollegejournal.org/ effects-of-a-culturally-relevant-educational-intervention-on-collegeretention-among-american-indian-tribal-college-students/

Indian Health Service. (2019). Disparities. U.S. Department of Health and Human Services. https://www.ihs.gov/newsroom/factsheets/ disparities/

Maurrasse, D. (2002). Higher education-community partnerships: Assessing progress in the field. Nonprofit and Voluntary Sector Quarterly, 31(1), 131-139. https://doi.org/10.1177/ 0899764002311006

National Association of Social Workers. (n.d.). Why choose the social work profession? https://www.socialworkers.org/Careers/Career-Center/ Explore-Social-Work/Choose-the-Social-Work-Profession

National Indian Council on Aging. (2019). American Indian suicide rate increases. https://www.nicoa.org/national-americanindianand-alaska-native-hope-for-life-day/

National Indian Health Board. (2020). National tribal behavioral health agenda. https://www.nihb.org/behavioral_health/ behavioral_health_agenda.php

National Inquiry into Missing and Murdered Indigenous Women and Girls (Canada). (2019). Reclaiming power and place: The final report of the National Inquiry Into Missing And 
Murdered Indigenous Women and Girls (Vol. 1a). Privy Council Office. https://www.mmiwg-ffada.ca/final-report/

Native American Community Academy Inspired Schools Network. (2016). NACA inspired schools network resource hub: What is Indigenous education? https://kenabahatathlie.wixsite.com/ nisnresources

Salsberg, E., Quigley, L., Mehfoud, N., Acquaviva, K. D., Wyche, K., \& Silwa, S. (2017). Profile of the social work workforce. https://hsrc. himmelfarb.gwu.edu/sphhs_policy_workforce_facpubs/16/

Thompson, K. A., Posey, A. L., \& Manshack, L. K. (2020). American Indian social work students: Factors that influence success in graduate school. Journal of Evidence-Based Social Work, 17(1), 63-74. https://doi.org/10.1080/26408066.2019.1626786

United Nations Department of Economic and Social Affairs. (2015). Human rights. https://www.un.org/development/desa/ indigenouspeoples/mandated-areas1/human-rights.html

United Nations Entity for Gender Equality and the Empowerment of Women. (2020). Making Indigenous women and girls visible in the implementation of the UN Framework for the Immediate SocioEconomic Response to COVID-19 accessing funds through the multi-partner trust fund. https://www.un.org/development/desa/ indigenouspeoples/wp-content/uploads/sites/19/2020/04/Prioritizingindigenous-women-in-the-MPTF-April-2020.-UN-Women.pdf

United Nations General Assembly. (1948). Universal declaration of human rights. https://www.un.org/en/universal-declarationhuman-rights/

United Nations General Assembly. (2007). Declaration on the rights of Indigenous people. https://www.un.org/development/desa/indig
enouspeoples/wp-content/uploads/sites/19/2018/11/UNDRIP_E_ web.pdf

Urban Indian Health Institute. (2018). Missing and murdered Indigenous women and girls. https://www.uihi.org/wp-content/uploads/2018/11/ Missing-and-Murdered-Indigenous-Women-and-Girls-Report.pdf

U.S. Census Bureau. (2012). The American Indian and Alaska Native population: 2010. U.S. Department of Commerce, Economics and Statistics Administration. https://www.census.gov/history/ $\mathrm{pdf} / \mathrm{c} 2010 \mathrm{br}-10 . \mathrm{pdf}$

Wayne, J., Bogo, M., \& Raskin, M. (2010). Field education as the signature pedagogy of social work education. Journal of Social Work Education, 46(3), 327-339.

World Health Organization. (2017). Human rights and health. https://www.who.int/news-room/fact-sheets/detail/ human-rights-and-health

World Health Organization. (2005). Mental health, human rights and legislation. https://www.who.int/mental_health/policy/legislation/ en/

Young, S., Zubrzycki, J., Green, S., Jones, V., Stratton, K., \& Bessarab, D. (2013). "Getting it right: Creating partnerships for change": Developing a framework for integrating Aboriginal and Torres Strait Islander knowledges in Australian social work education. Journal of Ethnic and Cultural Diversity in Social Work, 22(3-4), 179-197. https://doi.org/10.1080/15313204.2013.843120

Publisher's Note Springer Nature remains neutral with regard to jurisdictional claims in published maps and institutional affiliations. 